\title{
ASSESSMENT SYSTEM AND EMPIRICAL STUDY ON CHINA'S LOCAL GOVERNANCE QUALITY
}

\author{
JIE TANG ${ }^{1}$, JIANDANG LIU ${ }^{1}$, DONG WANG ${ }^{1}$, WEITENG LIN ${ }^{2} \&$ CHANG SU ${ }^{1}$ \\ ${ }^{1}$ School of Economics and Management, Harbin Institute of Technology (Shenzhen), China. \\ ${ }^{2}$ School of Civil and Environment Engineering, Harbin Institute of Technology (Shenzhen), China.
}

\begin{abstract}
Good governance is an important guarantee for the sustainable development of regional economy. Since the Reform and Opening-up, China's local economic development has made remarkable achievements, which has aroused the concern of the academic community. The main contents of China's local governance quality assessment include: government capacity, marketization, and rule of law, which means a new multidimensional perspective on local governance assessment: "power allocation + governance capacity + rule of law". This paper designs the index system of China's local governance assessment based on literature investigation and coefficient of variation, which utilizes two approaches: qualitative analysis and quantitative analysis. Furthermore, the investigation analyzes the panel data (2001-2014) of provincial regions in China by utilizing global factor analysis and weighted average. The results indicate that the improvements in government capacity, marketization, and rule of law were higher in the majority of provinces studied in central and western China between 2001 and 2014, while they were lower in most of provinces researched in northeastern China in the same period, which resulted from policy differences. In 2014, government capacity, marketization, and rule of law were higher in the majority of provinces investigated in eastern China, while they were lower in most of provinces surveyed in the rest of China, which was due to the differences in policies support, resources management, absolute geographical location, per capita GDP, and market economy. In order to improve local governance quality and achieve sustainable economic growth, it is very important to establish local governance structure as "effective government + efficient market", China should pay more attention to weak aspects of local governance and some provincial regions in western, central and northeastern China.

Keywords: China, government capacity, local governance, marketization, rule of law, sustainable development.
\end{abstract}

\section{INTRODUCTION}

With the extensive application of the word (governance) in various contexts, the connotation of governance has been changing. The original meaning of governance in English was guidance, control or manipulation [1,2]. Later, lots of scholars gave the word many new meanings. Douglas North proposed a basic concept of governance-limited government (rule of law) that protected private property from being grabbed by state [3]. Faguet [4] insisted that governance emphasized balanced federal system between central government and local governments (decentralization), and provided open access to firms (marketization), non-governmental organizations and citizen participation. As the two investigations above paid little attention to the institution (the state) that accumulates and uses power, Max Weber analyzed the state from a bureaucratic perspective, and defined the ideal type of modern bureaucracy from ten aspects for the first time [5]. Marcus and Andrew [6] investigated the state from a capacity perspective, and defined governance as the state ability to formulate and implement its goals. Further, Fukuyama [5] defined governance as "a government's ability to make and enforce rules, and to deliver services, regardless of whether that government is democratic or not". Rotberg [7] pointed out that bureaucracy and capacity were inputs, but governance should emphasize outputs, so he defined governance as the public service provided by government, that was, "good governance means results and 
performance" [8]. Based on existing literatures, Jiandang et al. [9] sorted out the connotation of governance from five perspectives: power allocation (decentralization or marketization), supervising power (rule of law), bureaucracy (procedures), government capacity, and government performance (output).

Since 1979, the local governance in China has changed a lot, its evolution can be understood from six key aspects: The first is marketization that means market, instead of government, has played an increasingly important role in resource allocation, and non-state enterprises have developed rapidly $[10,11]$, which have led to a significant increase in resource allocation efficiency. The second is the development of civil society, including the development of non-governmental organizations and non-profit organizations, and civic participation in public affairs, rather than in political elections or decisions on government personnel, resulting in mutual empowerment between government and society [10, 12, 13]. The third is community/villager autonomy, that is, residents/villagers can elect their representatives to fulfill duties such as management, supervision and service et al., which is the main form of grass-roots democracy in China $[10,12,14,15]$. The fourth is decentralization which means the provincial governments give some economic and social management power to municipal or county governments, helping local governments perform duties, serve residents, and develop economy $[12,16,17]$. The fifth is service-oriented government, instead of control-oriented government, which includes emphasizing government responsibility, increasing public services expenditure, improving relevant regulations and policies, raising the quality of government services, and equalizing basic public services $[10,18]$. The sixth is rule of law embodied in three dimensions of "text-actionconcept", namely, realizing the rule of law in local institutional systems, action systems, and conceptual systems [10,19].

With the evolution of local governance in China, the quantification of the concept seems to be very necessary, therefore, the quantitative research on local governance becomes the new focus of political science in China [20]. According to the administrative level of regions studied, the existing literature can be divided into three categories. The first category is province governance. Xuehua and Shengju [21] put forward the assessment system of public governance efficiency from three aspects (system, policy and behavior), and concluded that the assessment system was objective, scientific and reasonable after empirical investigation, but they only covered the cross-sectional data of five provincial regions in China. Based on the government management competitiveness indicators of China's regional competitiveness development report (2004, 2005), Wilson [22] got the composite governance indexes of 29 provincial regions (1985-2005) which were not comparable between different years, and found a clear variation across provinces, with the developed provinces enjoying better governance than the undeveloped provinces. On the basis of public service output, Fa and Chenying [23] measured the social governance level index of 31 provinces in China (2007-2014), with the comprehensive indexes comparable between different years, and got no $\sigma$ convergence in east, middle, west, and northeast of China, while there was absolute $\beta$ convergence among provinces, with a convergence speed of $7.93 \%$ per year. By learning from WGI (World Governance Index), Yang et al. [24] utilized 10231 questionnaires covering 31 provincial regions collected by CGSS (Chinese General Social Survey) in 2010, evaluated the governance level of provincial government from four aspects (Government Effectiveness, Rule of Law, Control of Corruption, Regulatory Quality), and thought that good governance was conducive to public happiness. Besides, their perspectives were different in governance assessment, Fa and Chenying [23] only focused on "output", while 
Wilson [22] focused on "government capacity + output", Yang et al. [24] chose "government capacity + rule of law", and Xuehua and Shengju [21] emphasized on "government capacity + rule of law + output".

The second category is urban governance. In 2006, the World Bank [25] published a report on the governance level of 120 cities in China's provinces except Tibet, paying attention to the feelings and perceptions of business people about urban governance quality, focusing on "government capacity + output", and believed that six cities (Hangzhou, Qingdao, Shaoxing, Suzhou, Xiamen and Yantai) were excellent in overall investment climate (for foreign enterprises), government efficiency (for domestic enterprises), and promotion of "harmonious social construction". In 2016, Unirule Institute of Economics [26] released Public Governance Index in 30 Capital Cities (2015) which has both objective and subjective indicators (questionnaire surveys), focusing on "power allocation + output", and suggested that cities could be divided into four types: open coastal cities, divided middle cities, planned eastern cities, and distorted other cities. The last category is township governance. Deyong [27] proposed the index system of China's township governance assessment for the first time, focusing on "government capacity + rule of law + output", and selected 20 townships in 10 provincial regions to do factor analysis based on the field survey data (2221 villagers' questionnaires), calculating the index of governance in 20 townships, with a conclusion that the level of democracy and social welfare affected the level of township governance.

Building upon previous literature, this paper presents an analysis on the quality assessment of China's local governance from three aspects: government capacity, marketization, and rule of law. The contribution of this study are highlighted as follows: (1) to develop a new multidimensional perspective on China's local governance assessment: "power allocation + governance capacity + rule of law", while Fa and Chenying [23] focused on "output", Unirule Institute of Economics [26] emphasized on "power allocation + output", and Deyong [27] chose "government capacity + rule of law + output". (2) to determine the index system by using two methods including qualitative analysis (literature investigation) and quantitative analysis (coefficient of variance), while existing literatures about China's local governance evaluation focused mainly on qualitative analysis only [21, 22, 27]. and (3) to provide new empirical investigation on China's provincial governance quality assessment by using the panel data (2001-2014) and calculating three sub-indices of provincial governance quality comparable between different years, while Xuehua and Shengju [21] chose crosssectional provincial data, and Wilson [22] focused on different panel data (1985-2005) in provincial regions, with the governance index uncomparable between different years.

The rest of this paper is organized as follows: Section 2 introduces approaches that are used to determine the weight, to calculate the sub-index, to evaluate the indicators, and constructs the assessment framework and the index system. Section 3 discusses the empirical results and its reasons. Section 4 concludes this paper and proposes some recommendations.

\section{METHODOLOGY}

\subsection{Methods and data}

\subsubsection{Calculating the sub-index}

According to the existing researches, the calculation approaches of governance quality index mainly include: MCDA(Multicriteria Decision Analysis) [28], weighted average method, and 
Table 1: The calculation methods of sub-indexes of governance quality [29].

\begin{tabular}{ll}
\hline Sub-indexes & Parameters \\
\hline Government capacity & Weighted average sum of individual indicators \\
Marketization & Weighted average sum of individual indicators \\
Rule of law & Weighted average sum of individual indicators \\
\hline
\end{tabular}

arithmetic average method, et al. Since the weight of each indicator may be different, this paper selects the weighted average method. However, the sub-indexes (government capacity, marketization, and rule of law) are only numbers relative to the base year, describing the relative level of governance quality. The calculation methods of sub-indexes of governance quality are demonstrated in Table 1.

\subsubsection{Nondimensionalizing the indicator}

The linear nondimensionalization has six main methods [30]: vector specification method, efficiency coefficient method, linear proportional method, normalization method, extreme value processing method, and normalization method. In order to accurately characterize the sample data, this paper chooses the adjusted linear scale method and sets 2001 as the base year. In base year, the maximum score of the non-dimensioned individual indicator is 100 , while other score is between 0 and 100 for the same individual indicator. In order to make each indicator comparable between different years, this paper learn from the dimensionless approach of Gang et al. [31], taking the maximum original data in base year as standard to carry out nondimensionalization for each year after 2001, resulting in the score more than or less than 100. The indicator score can be calculated as follows:

$$
j \text { indicator score of } i \text { province }=\frac{100 X_{i j}}{M_{j}}
$$

where $X_{i j}$ is the actual variable value, $M_{j}$ is the maximum value of the $j$ indicator in 2001 .

\subsubsection{Determining the weight}

According to the sources difference of original data, the determination of indicator weight can be divided into two categories [32]: one category is the objective assignment method, another is the subjective assignment method. The global factor analysis is based on classical principal component, and is a fusion of time series analysis and factor analysis. Therefore, the global factor analysis can be applied, the main steps are as follows [33]:

Firstly, determining the global principal factor equations:

$$
\begin{aligned}
& F_{1}=K_{11} * X_{1}+K_{21} * X_{2}+\ldots+K_{m 1} * X_{m} \\
& F_{2}=K_{12} * X_{1}+K_{22} * X_{2}+\ldots+K_{m 2} * X_{m} \\
& F_{n}=K_{1 n} * X_{1}+K_{2 n} * X_{2}+\ldots+K_{m n} * X_{m}
\end{aligned}
$$


where $F_{n}$ is expressed as the $n$th global principal factor, $X_{m}$ is the dimensionless value of the $m$ th variable, $K_{m n}$ is the coefficient of the $m$ th variable in the $n$th global principal factor; generally $n<m$, which embodies the idea of reducing the dimension in factor analysis.

Secondly, constructing a comprehensive assessment score equation:

$$
\begin{aligned}
Z F & =\left(\lambda_{1} * F_{1}+\lambda_{2} F_{2}+\ldots+\lambda_{n} F_{n}\right) /\left(\lambda_{1}+\lambda_{2}+\ldots+\lambda_{n}\right) \\
& =\beta_{1} * X_{1}+\beta_{2} * X_{2}+\ldots+\beta_{m} * X_{m}
\end{aligned}
$$

where $Z F$ is the comprehensive assessment score of governance quality, $\lambda_{n}$ is the variance contribution rate of the $n$th global principal factor, $\beta_{m}=\left(\lambda_{1} * K_{m 1}+\lambda_{2} * K_{m 2}+\ldots+\lambda_{n} * K_{m n}\right) /$ $\left(\lambda_{1}+\lambda_{2}+\ldots+\lambda_{n}\right)$.

Thirdly, calculating the weight of indicator variable $X_{i}$ :

$$
W_{i}=\left|\beta_{i}\right| /\left(\left|\beta_{1}\right|+\left|\beta_{2}\right|+\ldots+\left|\beta_{m}\right|\right)
$$

\subsubsection{Evaluating the indicator}

Based on the existing literatures [34], this paper uses the $C V$ (coefficient of variance) to evaluate and select the indicator. If most values of one indicator are similar, the $C V$ will be relatively small, indicating that the indicator can be deleted since it lacks effectiveness; otherwise, the indicator can be accepted. In general, the $C V$ is calculated as follows:

$$
\begin{gathered}
C V=\frac{S}{\bar{X}} \\
S=\sqrt{\frac{1}{n-1} \sum\left(X_{i}-\bar{X}\right)^{2}} \\
\bar{X}=\frac{1}{n} \sum X_{i}
\end{gathered}
$$

where $C V$ is the coefficient of variation, $S$ is the standard deviation of one indicator, $\bar{X}$ is the mean of one indicator, $n$ is the number of samples, $X_{i}$ is the $i$ th sample value of one indicator.

\subsubsection{Sample and data}

With the original data of indicator "rule of law" unavailable in Gansu, Guangxi, Inner Mongolia and Tibet, this article only focuses on the other 27 provincial regions. Central China includes 6 provincial regions: Shanxi, Hubei, Hunan, Anhui, Jiangxi, and Henan. Western China includes 8 provincial regions: Shaanxi, Ningxia, Xinjiang, Sichuan, Yunnan, Chongqing, Qinghai, and Guizhou. Eastern China includes 10 provincial regions: Beijing, Shanghai, Tianjin, Zhejiang, Jiangsu, Guangdong, Shandong, Fujian, Hainan, and Hebei. Northeastern China includes 3 provincial regions: Liaoning, Jilin, and Heilongjiang. Taking the consistency and actual availability of data into consideration, the data period is 14 years (2001-2014). If the original data is missing, this paper would deal with that by using the linear estimation method or similar indicator substitution method. The number of actual missing samples is 18 , accounting for $4.76 \%$ of the total samples, so the column deletion method can be applied, with 360 samples left. The original data in this paper comes from: China Statistical Yearbook (2002-2015), China Science and Technology Statistical Yearbook (2002-2015), Statistical Yearbook (2002-2015) in each provincial region. 


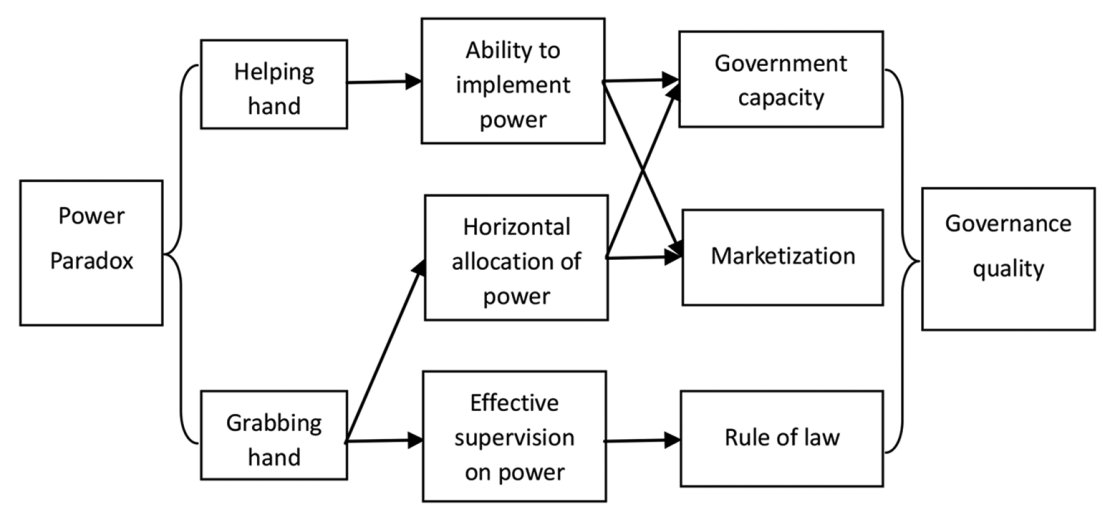

Figure 1: Assessment framework of China’s local governance quality.

\subsection{Framework and indicator}

\subsubsection{Assessment framework}

Although Power Paradox has been appearing in the process of local economic growth since 1979, local economic growth has responded well to this problem according to the past development achievements in China. Based on the evolution characteristics of local governance, this article puts forward the main contents of China's local governance quality assessment: government capacity, marketization, and rule of law. Among them, government capacity and marketization not only mean the horizontal allocation of power [4], but also mean the ability to implement power [5], while rule of law means the effective supervision on power [29]. Figure 1 shows the assessment framework of local governance quality in China.

\subsubsection{Index system}

Based on the main assessment contents of China's local governance quality, as well as the existing literature [11, 21-27, 29, 35], this paper puts forward the assessment index system of China's local governance quality by taking into account the validity and availability of data on the basis of sufficient comparison. The index system is intuitively demonstrated in Table 2.

In addition to theoretical analysis based on existing literatures, this paper uses CV to quantitatively evaluate the index system and to select the proper indicators. The result shows that the maximum $C V$ of indicators is 3.46 (technology market) and the minimum $C V$ is 0.40 (medical care). Yan [34] set the critical value of $C V$ at 0.3 , and Wei [36] at 0.2. Therefore, the variability of all indicators can meet the requirement, which demonstrates good identification ability, so all indicators should be accepted.

\section{RESULTS AND DISCUSSIONS}

\subsection{Descriptive statistics}

By learning from the existing literatures, this paper adopts kurtosis and skewness to check the normality of raw data, resulting in eight original variables that are not subject to normal 
Table 2: Index system of China's local governance quality assessment [29]

\begin{tabular}{|c|c|c|}
\hline Dimensions & Indicators & Parameters (unit) \\
\hline \multirow{5}{*}{$\begin{array}{l}\text { Government } \\
\text { capacity }\end{array}$} & Financial resource & Local finance revenue (yuan) / inhabitant \\
\hline & Infrastructure & $\begin{array}{l}\text { Standard highway mileage (meter) / area } \\
\left(\mathrm{km}^{2}\right)\end{array}$ \\
\hline & Innovation subsidy & $\begin{array}{l}\text { Government expenditures in science and } \\
\text { technology (yuan) / inhabitant }\end{array}$ \\
\hline & Education development & $\begin{array}{l}\text { Government expenditures in education } \\
\text { (yuan) / inhabitant }\end{array}$ \\
\hline & Medical care & Number of medical technicians / inhabitant \\
\hline \multirow[t]{5}{*}{ Marketization } & Non-state-owned output & $\begin{array}{l}\text { Non-state-owned industrial output (thousand } \\
\text { yuan) / area }\left(\mathrm{km}^{2}\right)\end{array}$ \\
\hline & $\begin{array}{l}\text { Non-state-owned } \\
\text { employment }\end{array}$ & $\begin{array}{l}\text { Number of employees in private and } \\
\text { individual enterprises / area }\left(\mathrm{km}^{2}\right)\end{array}$ \\
\hline & $\begin{array}{l}\text { Non-state-owned } \\
\text { investment }\end{array}$ & $\begin{array}{l}\text { Non-state-owned investment in fixed assets } \\
\text { (ten thousands yuan) / area }\left(\mathrm{km}^{2}\right)\end{array}$ \\
\hline & Technology market & $\begin{array}{l}\text { Technical market transaction value (yuan) / } \\
\text { inhabitant }\end{array}$ \\
\hline & Factor market & $\begin{array}{l}\text { Foreign direct investment (hundred yuan) / } \\
\text { area }\left(\mathrm{km}^{2}\right)\end{array}$ \\
\hline \multirow[t]{4}{*}{ Rule of law } & Lawyer & Number of lawyers / inhabitant \\
\hline & Litigation business & Number of litigation businesses/ inhabitant \\
\hline & Law office & Number of law offices / inhabitant \\
\hline & $\begin{array}{l}\text { Intellectual property } \\
\text { protection }\end{array}$ & Number of patent applications / inhabitant \\
\hline
\end{tabular}

distribution. After taking the natural logarithm of original data, the absolute values of all skewness are less than 2 while the absolute values of all kurtosis are less than 3 , which mean the new data approximately obeys the normal distribution. Based on the new data, we can get the mean, median, minimum, and maximum, which are showed in Table 3. As we can observe, the median is smaller than the mean in some variables such as financial resource, innovation subsidy, medical care, non-state-owned investment, lawyer, litigation business, law office, and intellectual property protection, which indicates most provincial regions were lower in these aspects. Among them, four indicators (lawyer, litigation business, law office, and intellectual property protection) belong to the rule of law, three indicators belong to the government capacity, one indicator belongs to the marketization.

\subsection{Government capacity}

Among the top 50\% provinces in 2014, Hubei is in central China, accounting for $1 / 6$ of provinces investigated in the region; Liaoning belongs to northeastern China, 1/3 of provinces studied; Shaanxi, Chongqing and Ningxia is in the west of China, 3/8 of provinces 
Table 3: Descriptive statistics

\begin{tabular}{llllccc}
\hline Indicators & Mean & Median & Minimum & Maximum & Kurtosis & Skewness \\
\hline Financial resource & 7.49 & 7.48 & 5.57 & 9.85 & -0.75 & 0.15 \\
Infrastructure & 6.50 & 6.65 & 3.69 & 7.91 & 1.71 & -1.22 \\
Innovation subsidy & 4.63 & 4.34 & 2.28 & 8.40 & 0.57 & 0.82 \\
Education & 6.35 & 6.45 & 4.59 & 8.15 & -1.13 & -0.07 \\
development & & & & & & \\
Medical care & 1.45 & 1.42 & 0.68 & 2.74 & 1.08 & 0.65 \\
Non-state-owned & 5.528 & 5.532 & 1.52 & 9.59 & 0.80 & -0.20 \\
output & & & & & & \\
Non-state-owned & 5.21 & 5.33 & 0.09 & 8.89 & -0.19 & -0.35 \\
employment & & & & & & \\
Non-state-owned & 6.72 & 6.56 & 0.46 & 11.89 & 1.10 & 0.49 \\
investment & & & & & & \\
Technology market & 8.03 & 8.18 & 1.23 & 12.73 & -0.11 & -0.36 \\
Factor market & 6.97 & 7.18 & 0.01 & 12.08 & -0.11 & -0.31 \\
Lawyer & 2.47 & 2.37 & 0.75 & 4.74 & 2.20 & 1.04 \\
Litigation business & 2.65 & 2.60 & 0.85 & 4.13 & 0.05 & 0.33 \\
Law office & 2.47 & 2.38 & 1.48 & 4.49 & 2.08 & 1.33 \\
$\begin{array}{l}\text { Intellectual property } \\
\text { protection }\end{array}$ & 3.41 & 3.27 & 0.83 & 6.46 & -0.74 & 0.33 \\
\hline
\end{tabular}

investigated; the other 8 provinces belong to eastern China, $80 \%$ of provinces researched. Apparently, the government capacity was strong in the east of China, while it was weak in the rest of China, especially in the middle of China, which implied a great governance difference between regions in China. There were several reasons for that: Firstly, since 1979, China's central government had paid lots of attention to eastern China, while less attention had been paid to western, northeast and central China, resulting in less funds, policies and opportunities for these three regions to develop, especially in the middle of China (the last one to get policies support from central government). Secondly, the resources management were totally different, because eastern China spent lots of resources, while other three regions just spent less resources, e.g. in 2014, Beijing spent 4436 yuan per habitant on innovation subsidy and 3449 yuan per habitant on education development, the highest level in China's provincial regions, while Yunnan spent 72 yuan on innovation, and Hebei spent 1177 yuan in education, both were the lowest level. Thirdly, the level of economic development was lower in the three regions (especially in the middle of China), because no province entered the high-income group whose standard was published by the World Bank annually, which led to local governments paying less attention to innovation investment.

From 2001 to 2014, the rankings rose in 13 provinces accounting for about $50 \%$ of provinces studied, while the rankings declined in 9 provinces accounting for about $30 \%$ of those; in eastern China, the rankings raised in $30 \%$ of provinces investigated, while the rankings descended in $30 \%$ of them; in central China, the rankings rose in $2 / 3$ of provinces studied, while the rankings fell in $1 / 6$ of them; in western China, the rankings went up in $3 / 4$ of prov- 
Table 4: The rankings of provincial government capacity in China

\begin{tabular}{|c|c|c|c|}
\hline Regions & Rankings in 2001 & Rankings in 2014 & Rankings Change \\
\hline Beijing & 1 & 1 & 0 \\
\hline Shanghai & 2 & 2 & 0 \\
\hline Tianjin & 3 & 3 & 0 \\
\hline Liaoning & 4 & 8 & -4 \\
\hline Jiangsu & 5 & 6 & -1 \\
\hline Zhejiang & 6 & 5 & 1 \\
\hline Guangdong & 7 & 7 & 0 \\
\hline Jilin & 8 & 14 & -6 \\
\hline Shanxi & 9 & 20 & -11 \\
\hline Shaanxi & 10 & 4 & 6 \\
\hline Hubei & 11 & 11 & 0 \\
\hline Heilongjiang & 12 & 16 & -4 \\
\hline Ningxia & 13 & 12 & 1 \\
\hline Shandong & 14 & 9 & 5 \\
\hline Fujian & 15 & 13 & 2 \\
\hline Hainan & 16 & 19 & -3 \\
\hline Xinjiang & 17 & 24 & -7 \\
\hline Hebei & 18 & 26 & -8 \\
\hline Sichuan & 19 & 15 & 4 \\
\hline Yunnan & 20 & 27 & -7 \\
\hline Chongqing & 21 & 10 & 11 \\
\hline Hunan & 22 & 17 & 5 \\
\hline Qinghai & 23 & 21 & 2 \\
\hline Anhui & 24 & 18 & 6 \\
\hline Jiangxi & 25 & 22 & 3 \\
\hline Henan & 26 & 25 & 1 \\
\hline Guizhou & 27 & 23 & 4 \\
\hline
\end{tabular}

inces researched, while the rankings went down in $1 / 4$ of them; in northeast China, the rankings declined in all provinces investigated. Obviously, government capacity was greatly improved in most of provinces studied in central and western China because of effective policies support (Western Development launched in 2000 and Middle Rises launched in 2004) from central government. The rankings of provincial government capacity in China are demonstrated in Table 4. 


\subsection{Marketization}

Among the top 50\% provinces in 2014, Chongqing is in the west of China, accounting for $1 / 8$ of provinces investigated in the region; Liaoning belongs to northeastern China, $1 / 3$ of provinces studied; Hubei, Anhui and Henan are in the central China, one half of provinces researched; Shanghai, Beijing, Tianjin, Jiangsu, Guangdong, Shandong, Zhejiang and Fujian belong to the east of China, $80 \%$ of provinces investigated. Obviously, the marketization was high in most of provinces studied in eastern China, while it was low in the rest of China, especially in the west of China. There were three reasons as follows: Firstly, the three regions (especially western China) lagged far behind eastern China in reform and opening up, because China's opening to the outside world started from the coastal special economic zone, and later gradually expanded to the coastal open city, the coastal economy open area, then to the middle of China, and finally to western China. Secondly, there were lots of state-owned enterprises in northeastern, central and western China, which were the representative of the planned economy, and hindered the development of market economy and non-state-owned enterprises. Thirdly, the inland location of the three regions (especially western China) disadvantaged them, because the cost was very high for them without ports to trade with other countries, and it was inconvenient to attract FDI (foreign direct investment).

From 2001 to 2014, the rankings rose in 13 provinces accounting for about $50 \%$ of provinces studied, while the rankings declined in 9 provinces accounting for about $30 \%$ of those; in eastern China, the rankings raised in about $30 \%$ of provinces investigated, while the rankings descended in about $50 \%$ of them; in central China, the rankings rose in 5/6 of provinces studied while keeping unchanged in $1 / 6$ of them; in western China, the rankings went up in $5 / 8$ of provinces researched while going down in $1 / 4$ of them; in northeast China, the rankings did not change in $1 / 3$ of provinces investigated while declining in $2 / 3$ of them. Apparently, the marketization was significantly improved in most of regions researched in middle and western China where local governments tried their best to develop market economy. The rankings of provincial marketization in China are showed in Table 5.

\subsection{Rule of law}

Due to the incomplete data in Hebei, Yunnan and Hainan, only 24 provincial regions could be analyzed here. Among the top 50\% provinces in 2014, Liaoning is in the northeast of China, accounting for $1 / 3$ of provinces investigated in the region; Chongqing, Ningxia and Shaanxi belong to western China, 3/7 of provinces studied; Beijing, Shanghai, Zhejiang, Tianjin, Jiangsu, Shandong, Guangdong and Fujian is in eastern China, 100\% of provinces researched. Obviously, the rule of law was high in provinces studied in the east of China, while it was low in other three regions, especially in central China. There were two reasons: Firstly, the market economy was undeveloped and the per capita GDP (Gross Domestic Product) was lower in the three regions (for example, the per capita GDP was lower in 5/6 of central China's provinces than in the whole China, while the per capita GDP was lower in 5/7 of western provincial regions, $1 / 3$ of northeastern provincial regions, and no eastern provincial regions), therefore local firms and inhabitants had no much idea about the rule of law, while China had a strong tradition of rule by man, so there were not strong needs for lawyers and lawyer offices in the three regions, especially in central China. Secondly, no province entered the high-income group in the three regions (especially in central China), which reveals the firms there paid less 
Table 5: The rankings of provincial marketization in China.

\begin{tabular}{|c|c|c|c|}
\hline Regions & Rankings in 2001 & Rankings in 2014 & Rankings Change \\
\hline Shanghai & 1 & 1 & 0 \\
\hline Tianjin & 2 & 3 & -1 \\
\hline Beijing & 3 & 2 & 1 \\
\hline Jiangsu & 4 & 4 & 0 \\
\hline Zhejiang & 5 & 7 & -2 \\
\hline Guangdong & 6 & 5 & 1 \\
\hline Shandong & 7 & 6 & 1 \\
\hline Liaoning & 8 & 8 & 0 \\
\hline Fujian & 9 & 12 & -3 \\
\hline Chongqing & 10 & 9 & 1 \\
\hline Hubei & 11 & 10 & 1 \\
\hline Hainan & 12 & 21 & -9 \\
\hline Hebei & 13 & 17 & -4 \\
\hline Henan & 14 & 13 & 1 \\
\hline Hunan & 15 & 15 & 0 \\
\hline Anhui & 16 & 11 & 5 \\
\hline Jilin & 17 & 20 & -3 \\
\hline Shaanxi & 18 & 16 & 2 \\
\hline Jiangxi & 19 & 14 & 5 \\
\hline Sichuan & 20 & 19 & 1 \\
\hline Heilongjiang & 21 & 22 & -1 \\
\hline Shanxi & 22 & 18 & 4 \\
\hline Ningxia & 23 & 24 & -1 \\
\hline Yunnan & 24 & 23 & 1 \\
\hline Guizhou & 25 & 25 & 0 \\
\hline Xinjiang & 26 & 27 & -1 \\
\hline Qinghai & 27 & 26 & 1 \\
\hline
\end{tabular}

attention to technology innovation, resulting in less patent applications and less needs for intellectual property protection.

From 2001 to 2014, the rankings rose in 10 provinces accounting for about $42 \%$ of provinces studied, while the rankings declined in 6 provinces accounting for about $25 \%$ of them; in eastern China, the rankings raised in $3 / 8$ of provinces investigated, while the rankings descended in $1 / 4$ of them; in central China, the rankings went up in a half of provinces 
Table 6: The rankings of provincial rule of law in China.

\begin{tabular}{|c|c|c|c|}
\hline Regions & Rankings in 2001 & Rankings in 2014 & Rankings Change \\
\hline Beijing & 1 & 1 & 0 \\
\hline Shanghai & 2 & 2 & 0 \\
\hline Tianjin & 3 & 4 & -1 \\
\hline Zhejiang & 4 & 3 & 1 \\
\hline Liaoning & 5 & 11 & -6 \\
\hline Guangdong & 6 & 6 & 0 \\
\hline Jiangsu & 7 & 5 & 2 \\
\hline Fujian & 8 & 9 & -1 \\
\hline Xinjiang & 9 & 15 & -6 \\
\hline Ningxia & 10 & 10 & 0 \\
\hline Heilongjiang & 11 & 16 & -5 \\
\hline Chongqing & 12 & 7 & 5 \\
\hline Shandong & 13 & 8 & 5 \\
\hline Jilin & 14 & 23 & -9 \\
\hline Shanxi & 15 & 18 & -3 \\
\hline Qinghai & 16 & 22 & -6 \\
\hline Shaanxi & 17 & 12 & 5 \\
\hline Hubei & 18 & 17 & 1 \\
\hline Hunan & 19 & 20 & -1 \\
\hline Sichuan & 20 & 13 & 7 \\
\hline Henan & 21 & 19 & 2 \\
\hline Anhui & 22 & 14 & 8 \\
\hline Jiangxi & 23 & 24 & -1 \\
\hline Guizhou & 24 & 21 & 3 \\
\hline
\end{tabular}

researched, while the rankings went down in the other half of them; in western China, the rankings rose in $4 / 7$ of provinces studied, while the rankings declined in 2/7 of them; in northeastern China, the rankings descended in all provinces researched. Apparently, the rule of law was improved significantly in most of provinces studied in the west of China, because local governments tried their best to protect private property and to improve business environment, in order to attract FDI and to develop local economy. The rankings of provincial rule of law are showed in Table 6. 


\section{CONCLUSIONS AND SUGGESTIONS}

\subsection{Conclusions}

Starting from North Paradox, this paper analyzes the main contents of China's local governance quality assessment, designs and evaluates the index system. Besides, by using global factor analysis method and weighted average method, this paper investigates the change trend of three sub-indices of local governance quality in China. The main conclusions are as follows:

Firstly, the main contents of China's local governance quality assessment include: government capacity, marketization, and rule of law. Among them, government capacity and marketization pertain to both the capacity of executing power [5] and the horizontal allocation of power [4], while rule of law belongs to the effective supervision on power [29]. The assessment index system presents a new multidimensional governance perspective of "power allocation + governance capacity + rule of law", which is different from the perspectives of Xuehua and Shengju [21] focusing on "government capacity + rule of law + output", Wilson [22] paying attention to "government capacity + output", Fa and Chenying [23] choosing "output", and Yang et al. [24] emphasizing on "government capacity + rule of law".

Secondly, in 2014, the government capacity was strong in most of provinces studied in eastern China, while it was weak in the rest of China, especially in central China. The capacity difference came from three aspects: (1) The east of China was the first region to get policies support from central government, while the middle of China was the last one. (2) The resources management were different. (3) The level of economic development was lower in the three regions, especially in the middle of China. Besides, from 2001 to 2014, government capacity was greatly improved in most of provinces investigated in central and western China because of the policies support (Western Development launched in 2000 and Middle Rises in 2004).

Thirdly, the marketization was high in most of provinces investigated in eastern China, while it was low in the rest of China in 2014. There were three reasons for the marketization difference: (1) The three regions lagged far behind eastern China in reform and opening up. (2) There were more state-owned enterprises in the three regions than in the east of China. (3) The inland location of the three regions disadvantaged them very much. Moreover, from 2001 to 2014, the marketization was significantly improved in most of regions researched in middle and western China where local governments tried their best to develop market economy.

Fourthly, the rule of law was high in provinces researched in the east of China, while it was low in other three regions in 2014. There were two reasons as follows: (1) The market economy was undeveloped and the per capita GDP was low in the three regions, while China had a strong tradition of rule by man. (2) No province entered the high-income group in the three regions. In addition, from 2001 to 2014, the rule of law was improved significantly in most of provinces studied in the west of China, because local governments tried their best to protect private property and to improve business environment, in order to attract FDI and to develop local economy.

\subsection{Policy recommendations}

The existing researches reveal that better governance enables developing countries to make full use of their later-mover advantage, achieving economic growth faster than developed 
countries. In 2016, China's per capita GDP was just over $\$ 8,800$, a long way from the average level in high-income countries. Therefore, it will be a very important task to continuously improve the quality of local governance in China. Based on the conclusions above, this paper proposes the following suggestions:

Firstly, according to the assessment contents of local governance quality in China, both market and government play an important role in local governance, therefore it is very important to establish local governance structure as "effective government + efficient market" [37-39]. Efficient market means that the market plays a key role in resource allocation, and effective government means that the government facilitates the role of market by providing development space, infrastructures, schools, hospitals, et al. Besides, market can facilitate the role of government by providing tax, goods, et al, resulting in mutual empowerment between government and market, by which the governance structure could be built quickly.

Secondly, most provincial regions were lower in indicators such as financial resource, innovation subsidy, medical care, non-state-owned investment, lawyer, litigation business, law office, and intellectual property protection, so more attention should be paid to these weak aspects of local governance, especially rule of law and government capacity: (1) Local governments should provide more access to lawyer industry, strengthen intellectual property protection, and cultivate citizens' legal ideology. (2) Central government should offer more finance resource to some local governments, and local governments could choose to provide more access to medical service industry. (3) Local governments should strengthen private property protection and improve local business climate to encourage non-state-owned investment.

Thirdly, compared with eastern China, the other three regions (western, central, and northeastern China) were lower in government capacity, marketization, and rule of law, therefore governments should pay more attention to these three regions, especially central China: (1) The middle of China, especially Shanxi, Henan, Anhui, Jiangxi and Hunan, should make full use of "Middle Rises" and funds from central government, and give priority to government capacity and rule of law while improving marketization. (2) The west of China, especially provincial regions except Chongqing, should grasp the opportunity of "Western Development", and give more attention to marketization while raising government capacity and rule of law. (3) The northeast of China, especially Heilongjiang and Jilin, should utilize "Rejuvenation of Northeast Old Industry Base", and strengthen rule of law, marketization and government capacity.

\section{REFERENCES}

[1] Jessop, B., The rise of governance and the risk of its failure: economic development as an example. International Social Science Journal (Chinese Edition), (1), pp. 31-48, 1999.

[2] Keping, Y., An introduction to governance and good governance. Marxism \& Reality, (5), pp. 37-41, 1999. (in Chinese)

[3] Kaufmann, D., Kraay, A. \& Mastruzzi, M., Growth and governance: a reply. Journal of Politics, 69(2), pp. 555-562, 2007. http://onlinelibrary.wiley.com/doi/10.1111/j.1468-2508.2007.00550.x/full

[4] Faguet, J., Decentralization and governance. World Development, 53, pp. 2-13, 2014. https://doi.org/10.1016/j.worlddev.2013.01.002

[5] Fukuyama, F., What is governance? Governance, 26(3), pp. 347-368, 2013. http://onlinelibrary.wiley.com/doi/10.1111/gove.12035/full 
[6] Marcus, J.K. \& Andrew, S., Growth and governance: models, measures, and mechanisms. Journal of Politics, 69(2), pp. 538-554, 2007.

http://onlinelibrary.wiley.com/wol1/doi/10.1111/j.1468-2508.2007.00549.x/citedby

[7] Rotberg, R.I., Good governance means performance and results. Governance, 27(3), pp. 511-518, 2014.

https://doi.org/10.1111/gove.12084

[8] Pinto, F., Simões, P. \& Marques, R., Raising the bar: the role of governance in performance assessments. Utilities Policy, 49, pp. 38-47, 2017. https://doi.org/10.1016/j.jup.2017.09.001

[9] Jiandang, L., Jie, T., Dong, W. \& Senlin, Zh., Governance: origin, connotation and application. 2016 5th EEM International Conference on Education Science and Social Science (EEM-ESSS 2016), 93, pp. 228-231, 2016. available at: http://apps. webofknowledge.com/full_record.do?product=WOS\&search_mode=GeneralSearch\& qid=1\&SID=5CrE4PQQxM9c7tTeVMV\&page $=1 \&$ doc $=1$

[10] Keping, Y., China's political reform towards good governance from 1978 to 2008. Jilin University Journal Social Science Edition, 48(3), pp. 5-17, 2008. (in Chinese)

[11] Xiaolu, W., Gang, F. \& Jingwen, Y., Marketization index of China's provinces: NERI report 2016, Social Sciences Academic Press (CHINA): Beijing, pp. 39-61, 2017. (in Chinese)

[12] Baocheng, M., The coordinated development of state and society-the new tendency of local governance in China. Journal of Shanghai Administration Institute, 9(6), pp. 38-44, 2008. (in Chinese)

[13] Jianxing, Y. \& Jun, Zh., Local governance and business associations in Wenzhou: a model for the road to civil society in China? Journal of Contemporary China, 22(81), pp. 394-408, 2013. http://dx.doi.org/10.1080/10670564.2012.748959

[14] Zengke, H., Local governance innovations and modernization of local governance: case study on Guangdong Province. Journal of Public Management, 14(2), pp. 1-13, 2017. (in Chinese)

[15] Deyong, M. \& Zhengxu, W., Governance innovations and citizens' trust in local government: electoral impacts in China's townships. Japanese Journal of Political Science, 15(3), pp. 373-395, 2014. https://doi.org/10.1017/s1468109914000152

[16] Xiaokang, L., Yuan, F. \& Shaobo, W., Study on local government's capacity of the public service supply in the context of expanding counties' power. Chinese Public Administration, (3), pp. 75-79, 2011. (in Chinese)

[17] Fang, Ch. \& Zhenming, Ch., Citizen participation in local governance in contemporary China - history, current situation and prospect. Southeast Academic Research, (4), pp. 111-120, 2008. (in Chinese)

[18] Xinyu, D. \& Zhengwei, Zh., Local government innovation under the concept of serviceoriented government-empirical studies of $101 \%$ services of Huaian Municipal Government. Chinese Public Administration, (4), pp. 22-25, 2011. (in Chinese)

[19] Zitang, F. \& Shan'gen, Zh., Analysis of local rule of law construction and its assessment mechanism. Social Sciences in China, (11), pp. 123-143, 2014. (in Chinese)

[20] Leizhen, Z., The quantitative study of governance: theory evolution and reflectionA case of Worldwide Governance Indicators (WGI). Social Sciences Abroad, (4), pp. 11-16, 2012. (in Chinese) 
[21] Xuehua, Sh. \& Shengju, F., The design of public management efficiency assessment index system in China provincial government. Cass Journal of Political Science, (2), pp. 56-66, 2010. (in Chinese)

[22] Wilson, R., Does governance cause growth? Evidence from China. World Development, 79, pp. 138-151, 2016.

https://doi.org/10.1016/j.worlddev.2015.11.015

[23] Fa, T. \& Chenying, Zh., Social governance in China: index, convergence and influential factors. Public Finance Research, (8), pp. 54-65, 2016. (in Chinese)

[24] Yang, J., Xin, F. \& Xinyu, Zh., Government governance and public happiness. Management World, (3), pp. 172-173, 2017. (in Chinese)

[25] World Bank, Governance, investment climate, and harmonious society: competitiveness enhancement for 120 Cities in China, 2006.

[26] Unirule Institute of Economics, Public Governance Index in 30 Capital Cities (2015), 2015. (in Chinese)

[27] Deyong, M., Measuring township governance: an empirical study of 20 townships in 10 provinces and cities of China. Chinese Public Administration, (1), pp. 99-104, 2013. (in Chinese)

[28] Da Cruz, N. \& Marques, R., An application of a multicriteria model to assess the quality of local governance. Urban Affairs Review, 2017. (to be published)

[29] Jiandang, L., Xin D., Jie, T., Dong, W. \& Zhijun, L., The provincial governance quality in China: an empirical study of three dimensions. 2017 3rd International Conference on Creative Education (ICCE 2017), 13, pp. 179-184, 2017, available at http://apps .webofknowledge.com/full_record.do?product=WOS\&search_mode=GeneralSearch\& qid=1\&SID=7AVnEVe6FBDdIbhDZ3t\&page $=1 \&$ doc $=1$

[30] Yajun, G. \& Pingtao, Y., Character analysis of linear dimensionless methods. Statistical Research, 25(2), pp. 93-100, 2008. (in Chinese)

[31] Gang, F., Xiaolu, W., Liwen, Zh. \& Hengpeng, Zh., China regions' marketization relative process report. Economic Research Journal, (3), pp. 9-18, 2003. (in Chinese)

[32] Ye, X., Changqi, T. \& Hui, D., An empirical analysis on the coupling of regional industry innovation and industry upgrading: A case of the Pearl River Delta Region. Science Research Management, 36(4), pp. 109-117, 2015. (in Chinese)

[33] Huimin, L., Global factor analysis and spatial differentiation study on comprehensive carrying capacity of urban agglomeration in the Yangtze River delta. China Soft Science, (10), pp. 114-122, 2011. (in Chinese)

[34] Yan, Z., Research on assessment index system of innovative city and innovation capacity structure of China' key cities. Management review, 24(6), pp. 50-57, 2012. (in Chinese)

[35] Kai, L. \& Shaozhou, Q., Is the hypothesis "FDI Decreasing Energy Intensity of the Host Country" Valid in China?: based on empirical analysis of Chinese provincial industrial panel data. World Economy Studies, (3), pp. 108-122, 2016. (in Chinese)

[36] Wei, X., Songzheng, Zh. \& Lin, X., A study of the selection of assessment indexes of commercial bank's information technology risks. Finance Forum, (9), pp. 68-74, 2013. (in Chinese) 
[37] Dong, W. \& Jiandang, L., The model of urban governance in industrial transformation and upgrading: a study based on garment industry in Shenzhen. China Soft Science (supplement), pp. 328-340, 2014. (in Chinese).

[38] Jiandang, L., Jie, T. \& Dong, W., The urban governance and high-tech manufacturing upgrading in China's Latecomer City. 2016 3rd International Conference on Economic, Business Management and Education Innovation (EBMEI 2016), 54, pp. 14-20, 2016. available at: http://apps.webofknowledge.com/full_record.do?product=WOS\&search_ mode $=$ GeneralSearch \&qid $=1 \&$ SID $=8$ DSVTwB2bMLMhDPPmZG\&page $=1 \& \mathrm{~d}$ $\mathrm{oc}=1$

[39] Jiandang, L. \& Hui, Zh., On evolution and optimization of regional governance of Guangdong-HK-Macao areas. China Opening Journal, (3), pp. 70-73, 2012. (in Chinese). 